recent years these ligands have been studied for their capacity as conductors and in optical applications. ${ }^{0}$ Our objective is to use these previously reported ligands as well as novel ligands and coordinate them to various transition metals in order to prepare unique metal-organic frameworks (MOFs). Coordination of the ligand 1,4bis(4'-pyridyl)butadiyne, with $\mathrm{CuNO}_{3}$ has been shown to form square-grid architectures with the inclusion of methylene chloride solvent. This supramolecular material and other related examples have been investigated for their gas sorption abilities.

[1] N.R. Champness, A.N. Khlobystov, A.G. Majuga, M Schröder and N.V. Zyk, Tetrahedron Letters, 1999, 40, 5413.

[2] J. Gonzalo Rodriguez, R. Martin-Villamil, F.H. Cano and I. Fonseca, J. Chem. Soc., Perkin Trans. 1, 1997, 709.

[3] Md. B. Zaman, M.D. Smith, and HC. Zur Loye, Chem. Mater., 2001, 13, 3534

\section{MS13 P19}

A gating mechanism accounts for gas transport through calixarene crystals. Charl G. Marais, Jan A. Gertenbach, Leonard J Barbour and Catharine Esterhuysen. Department of Chemistry, University of Stellenbosch, South Africa. E-mail: charl@sun.ac.za

\section{Keywords: calixarene, gate-opening, storage}

Porous solids have attracted considerable attention owing to their unusual physico-chemical properties [1] and are of particular economic interest with regard to their potential applications in gas storage [2], separation and sensing [3].

Commercially, alternative safe storage mechanisms for acetylene, a highly reactive and dangerous gas, should be investigated as it plays a crucial part as a starting material in several chemical products and electronic materials $[1,4]$. Since it is important to purify acetylene for the manufacture of these materials, it is necessary to devise systems to separate acetylene from gas mixtures that also contain carbon dioxide and other impurities.

An investigation of gas transport and storage mechanisms in $t$-butylcalix[4/8/9]arenes using standard crystallographic and computational molecular force field techniques was conducted with a view to gaining greater insight into solid-gas interactions and solid-state dynamics. Furthermore, X-ray structural studies have also been undertaken in order to identify the active site within the guest-accessible voids.

Results from computational calculations were used to predict a mechanism for gas transport and storage. These findings are correlated with the crystallographic and sorption data. The investigation suggests that a gating mechanism is the driving force for gas transport and sequestration in the calixarene crystals.

[1] Kitagawa, S et al. Highly controlled acetylene accommodation in a metal-organic microporous material. Nature 436, 238-241 (2005).

[2] Zhao, X. et al. Hysteretic adsorption and desorption of hydrogen by nanoporous metal-organic frameworks. Science 306, 1012--1015 (2004).

[3] Bradshaw, D., Prior, T. J., Cussen, E. J., Claridge, J. B. \& Rosseinsky, M. J. Permanent microporosity and enantioselective sorption in a chiral open framework. J. Am. Chem. Soc. 126, 6106--6114 (2004).

[4] Stang, P. J. \& Diederich, F. Modern Acetylene Chemistry (VCH, New York, 1995).

\section{MS13 P20}

Porosity studies of wave-like, one-dimensional coordination polymers. Storm Potts, Liliana Dobrzańska, Martin W. Bredenkamp and Leonard J Barbour. Department of Chemistry, University of Stellenbosch, South Africa. E-mail: storm@sun.ac.za

Keywords: porous materials, coordination compounds, gas-solid interactions

The formation of porous crystalline materials is a central theme of our research efforts. Our approach is to design and prepare solvent-templated host-guest systems consisting of simple coordination compounds grown from common solvents. In general, the solvent molecules can be removed as single-crystal to single-crystal processes to afford porous or seemingly nonporous systems that are still permeable to various gases.

A range of such compounds have been characterised by Xray diffraction methods with supporting data obtained using thermogravimetry, sorption isotherms and modeling studies. Although we are primarily interested in forming discrete dinuclear complexes, we have also obtained interesting new results using wave-like one-dimensional coordination polymeric systems. These are obtained from the crystallization of $\mathrm{CuCl}_{2}: \mathbf{L}$ from 1,2-dichloroethane. We find that that the polymeric waves stack one over the other to form guest-accessible pockets of approximately $143 \AA^{3}$. We will present X-ray structural data as well as the results of gas sorption studies.

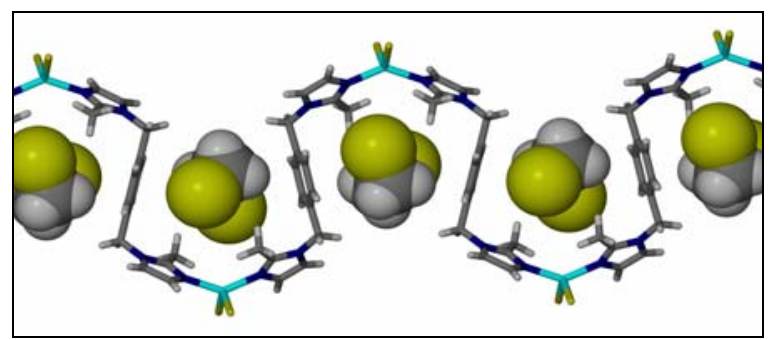

[1] L. Dobrzańska, G.O. Lloyd, H.G. Raubenheimer and L.J. Barbour, J. Am. Chem. Soc. 127, 13134 (2005).

MS13 P21

Crystal Structures and Properties of $\left[\mathbf{M}\left(\mathrm{NH}_{3}\right)_{5} \mathrm{Cl}_{2}\left[\operatorname{Re}_{6} \mathrm{~S}_{8}(\mathbf{C N})_{6}\right] \cdot 3 \mathrm{H}_{2} \mathrm{O}\right.$ Kirill Yusenko ${ }^{\mathrm{a}}$, Elena Shusharina ${ }^{\mathrm{b}}$, Iraida Baidina ${ }^{\mathrm{a}}$, Sergey Gromilov ${ }^{\mathrm{a}}$ Nikolaev Institute of Inorganic Chemistry, Novosibirsk, Russia. ${ }^{\mathrm{b}}$ Faculty of Natural Science, Novosibirsk State University, Russia. E-mail: yusenko@che.nsk.su

Keywords: clusters in coordination complexes, platinum group, rhenium

Using an inert $\left[\mathrm{M}\left(\mathrm{NH}_{3}\right)_{5} \mathrm{Cl}\right]^{2+}(\mathrm{M}=\mathrm{Rh}, \mathrm{Ir}, \mathrm{Ru})$ cations upon crystallisation of the salt with the $\left[\operatorname{Re}_{6} \mathrm{~S}_{8}(\mathrm{CN})_{6}\right]^{4-}$ anion makes possible the preparation of compounds with the island crystal structures containing the isolated cations and large cyanide anions. The compounds $\left[\mathrm{M}\left(\mathrm{NH}_{3}\right)_{5} \mathrm{Cl}\right]_{2}\left[\mathrm{Re}_{6} \mathrm{~S}_{8}(\mathrm{CN})_{6}\right] \cdot 3 \mathrm{H}_{2} \mathrm{O}(\mathrm{M}=\mathrm{Rh}(1) ; \mathrm{Ir}(2) ; \mathrm{Ru}$ (3)) have been synthesized by crystallization from aqueous solutions. The compounds are isostructural. They crystallize in the triclinic space group P-1 with the cell parameters for $1: \mathrm{a}=10.7574(7), \mathrm{b}=13.9423(9), \mathrm{c}=$ 14.7975(9) $\AA$, $\alpha=92.031(2) \AA, \beta=110.137(2), \gamma=$ $109.976(2)^{\circ}, V=1928.7(2) \AA^{3}$. 


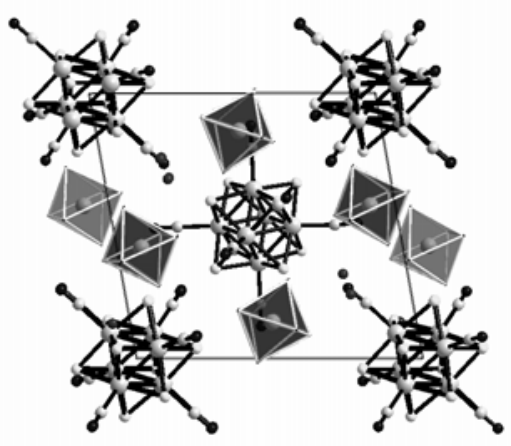

Thermal decomposition of the title compounds has been studied. Final products of thermal decomposition are single-phase hexagonal closed-packed metal solid solutions $\mathrm{Rh}_{0.25} \mathrm{Re}_{0.75}(\mathrm{a}=2.749(2), \mathrm{c}=4.395(3))$ and $\mathrm{Ir}_{0.25} \operatorname{Re}_{0.75}(\mathrm{a}=2.758(2), \mathrm{c}=4.393(3)) . \mathrm{Ru}_{0.25} \operatorname{Re}_{0.75}(\mathrm{a}=$ 2.756(2), c = 4.414(3) $\AA$ ).

\section{MS13 P22}

Synthesis And Structures Of Dicarboxylato-Bridged Earth-Alcaline Polymers ${ }^{1)}$ Aliouane. K. , (1) GuehriaLaidoudi A., ${ }^{(2)}$ Dahaoui S. and ${ }^{(2)}$ Lecomte C. ${ }^{a}$ Laboratoire de cristallographie appliquée, Institut de Chimie, U.S.T.H.B., B.P. 32, El-Alia 16111, Bab-Ezzouar, Alger, Algérie (2) LCM $^{3}$ B-CNRS UMR 7036, Faculté des Sciences Université Henri Poincaré BP 239, 54506 Vandoeuvre-lès-Nancy, France.

Keywords: polymeric structure, earth-alcaline, dicarboxylate

The binding of earth-alcaline ions to dicarboxylate ligands partially $\left[\mathrm{CO}_{2}\left(\mathrm{CH}_{2}\right)_{\mathrm{n}} \mathrm{CO}_{2} \mathrm{H}\right]^{-}$or completely $\left[\left(\mathrm{CH}_{2}\right)_{n}-\left(\mathrm{CO}_{2}\right.\right.$ )$\left._{2}\right]^{2-}$ deprotonated often lead to polymeric structures. The resulting model complexes are designed to permit the significance of interactions in such extended structures which are used in several fields, particularly in biology and medecine. An extensive polymeric arrays involving earth-alcaline ion depends on the geometric constraints of the metal ion. It is well known that barium, calcium and strontium exhibit a great flexibility if compared to magnesium, in which a rigid requirement of octahedral geometry is invariably found, preventing aggregation. However, in its hydrated $\alpha, \omega$ dicarboxylates, $\mathrm{Mg}$ realizes chain structure for small values of n (1 to 3$)$ and layer structure for higher values ${ }^{1}$.

The three anhydrous $\mathrm{Ba}, \mathrm{Ca}$ and $\mathrm{Sr}$ sebasate, have been synthesized. Single X-ray diffraction studies, carried out at $(293 \mathrm{~K})$ and $(120 \mathrm{~K})$, show that they contain partially deprotonated legands. Their space groups, centrosymmetric for $\mathrm{Sr}\left(\mathrm{P}_{2} / \mathrm{nbc}\right)$ and $\mathrm{Ca}(\mathrm{P}-1)$ complexes and non centrosymmetric for $\mathrm{Ba}(\mathrm{P}-4 \mathrm{~b} 2)$ point to the invalidity of $n$ parity criteria in the centrosymmetry. In the two tetragonal symmetries, the values of cell parameters, particularly c parametrer, provide evidence that this later, is not related to the lengthening of carbon backbone. The metals are eight-coordinated, and $\mu-1,3$ oxo-bridges, lead to a two-dimensional layered structure, exhibiting wide empty channels. The general structural features are very similar to those lanthanum complexes, obtained with a relatively long alkyl chain ${ }^{2}(n \geq 5)$, even though, the tetragonal symmetry seems to be, in the series, particular to anhydrous barium complexes whatever $n$ values ${ }^{3}$.

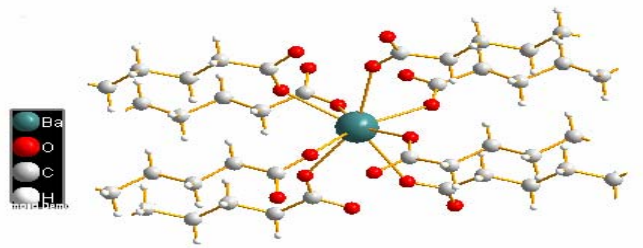

[1] J. Baier, U. Thewalt, Z. Anorg Allg. Chem., 628, 315-321, (2002).

[2] B. Benmerad, A. Guehria-Laidoudi, S. Dahaoui, C. Lecomte, Acta Cryst, C 60, m407-m409, (2004)

[3] A. Djeghri, these magister, Alger, (1999).

\section{MS13 P23}

The Study of Unprecedented Tubular Channels Formation in Alkyl-Substituted Oxamide Oxime Metal Complexes Yurii Chumakov, a, Dominique Luneau, Fatma Yuksel ${ }^{\mathrm{a}, \mathrm{c}}$, Vefa Ahsen $^{\mathrm{c,d}}$,, Gulay Gumus ${ }^{\mathrm{d}}$, Ilke Gurol ${ }^{\mathrm{d}}$. ${ }^{\mathrm{a}}$ Université Claude Bernard Lyon 1, France, ${ }^{b}$ Institute of Applied Physics of Academy of Science of Moldova, ${ }^{\mathrm{C}}$ Gebze Institute of Technology, ${ }^{\mathrm{d}}$ TUBITAKMarmara Research Center, Turkey

E-mail: iurii.ciumacov@univ-lyon1.fr

Keywords: oxamide oxime metal complexes, tubular channels, conformational analysis

It was found that nickel(II) and palladium(II) complexes of hexyl- substituted oxamide oxime are self-assembled through hydrogen bonds involving the oximic oxygens and amino nitrogen atoms to afford metal-organic frameworks with tubular channels partly filled by the hexyl chains [1]. But whether the chains cooperate in the formation of these structures, or simply fill the empty space, was unclear. Therefore, the nickel (II) (1a-3a) and palladium(II) $(\mathbf{1} \mathbf{b}-\mathbf{3 b}, \mathbf{5 b}, \mathbf{6 b})$ complexes of oxamide oximes substituted with alkyl chains of different length (C3-C8) were synthesized and characterized by X-ray and spectroscopic methods as well as their conformational analysis was carried out in order to understand the role of chains in formation of the tubular channels in the crystals. All studied molecules are centrosymmetric at the metal center forming the perfectly planar central cores containing the metal ion $[\mathrm{M}\{\mathrm{O} 1-\mathrm{N} 1-\mathrm{C} 1(\mathrm{~N} 3)-\mathrm{C} 2(\mathrm{~N} 4)-\mathrm{N} 2-\mathrm{O} 2\} 2]$ $[\mathrm{M}=\mathrm{Ni}(\mathrm{II}), \mathrm{Pd}(\mathrm{II})]$. It was found that only palladium(II) $(\mathbf{1 b}-\mathbf{3 b}, \mathbf{5 b}, \mathbf{6 b})$ complexes form the infinite tubular channels filled by the chains. The channels in these ones, as well as in nickel(II) (4a) and palladium(II) (4b) complexes [1], are walled by the central cores which are self-assembled via $\mathrm{N}-\mathrm{H} . . . \mathrm{O}$ hydrogen bonds involving the oximic oxygens and amino nitrogen atoms. The building blocks which form the crystal packing of $\mathbf{2 b - 6 b}$ and $4 \mathbf{a}$ have been extracted in order to perform the quantitative analysis of channels topology and they were characterized by the packing indexes. It was shown that the space in the channels which is filled by chains in compounds of $\mathbf{2 b}, \mathbf{3 b}, \mathbf{5 b}$ and $\mathbf{6 b}$ is greater in 2.6-3.6 times then in $\mathbf{4 a}$ and $\mathbf{4 b}$. On the base of conformational analysis using the module Conformational Search implemented in HyperChem 6.03 it was found that the formation of infinite tubular channels in the crystals of alkyl-substituted oxamide oxime nickel (II) and palladium (II) complexes depends on the orientation of the chains relatively to the 